\title{
Triacetyl resveratrol upregulates miRNA-200 and suppresses the Shh pathway in pancreatic cancer: A potential therapeutic agent
}

\author{
JUNSHENG FU $^{1}$, ANJU SHRIVASTAVA ${ }^{2}$, SUSHANT K. SHRIVASTAVA ${ }^{3}$, \\ RAKESH K. SRIVASTAVA ${ }^{4,6}$ and SHARMILA SHANKAR ${ }^{4-6}$
}

\author{
${ }^{1}$ College of Life Sciences, Fujian Agriculture and Forestry University, Fuzhou, Fujian 350002, P.R. China; \\ ${ }^{2}$ St. Joseph's Hospital and Medical Center, Phoenix, AZ 85013, USA; ${ }^{3}$ Pharmaceutical Chemistry Research Laboratory, \\ Department of Pharmaceutical Engineering and Technology, Indian Institute of Technology, Banaras Hindu University, \\ Varanasi, Uttar Pradesh 221005, India; ${ }^{4}$ Kansas City VA Medical Center, Kansas City, MO 66128; \\ ${ }^{5}$ Department of Pathology, School of Medicine, University of Missouri-Kansas City, Kansas City, MO 64108, USA
}

Received May 8, 2018; Accepted January 7, 2019

DOI: 10.3892/ijo.2019.4700

\begin{abstract}
Trans-3,4',5-trihydroxystilbene (resveratrol) is a naturally occurring polyphenolic phytoalexin with marked anticancer activities, and is mainly found in grapes, berries and peanuts. However, due to a low bioavailability, it has not progressed to clinical practice for cancer treatment. Therefore, the aims of the present study were to examine the anticancer activities of the resveratrol derivative, triacetyl resveratrol (TCRV), in pancreatic cancer cells. Apoptosis was measured by fluorescence-activated cell sorting and terminal deoxynucleotidyl transferase (TdT)-mediated dUTP nick-end labeling assays. Gene expression was measured by reverse transcription-quantitative polymerase chain reaction. TCRV inhibited colony formation and induced apoptosis through caspase-3 activation in human pancreatic cancer AsPC-1 and PANC-1 cells, whereas it exerted no effect on human pancreatic normal ductal epithelial cells (HPNE). TCRV inhibited epithelial-mesenchymal transition (EMT) by upregulating the expression of E-cadherin and suppressing the expression of $\mathrm{N}$-cadherin and the transcription factors, Snail, Slug and Zeb1. TCRV inhibited Zeb1 3'UTR-luciferase activity through the upregulation of microRNA (miR)-200 family members. The inhibitory effects of TCRV on pancreatic cancer cell migration and invasion were counteracted by anti-miR-200 family members. The inhibitory effects of TCRV on EMT and the induction of apoptosis were exerted through the suppression of
\end{abstract}

Correspondence to: Dr Junsheng Fu, College of Life Sciences, Fujian Agriculture and Forestry University, 15 Shangxiadian Road, Fuzhou, Fujian 350002, P.R. China

E-mail: fujunsheng81@163.com

Present address: ${ }^{6}$ Stanley S. Scott Cancer Center, Department of Genetics, Louisiana State University Health Sciences Center, New Orleans, LA 70112, USA

Key words: pancreatic cancer, triacetyl resveratrol, microRNA, epithelial-mesenchymal transition, sonic hedgehog pathway the sonic hedgehog (Shh) pathway, and through the modulation of cyclin D1 and Bcl-2 expression. The hyperactivation of the Shh pathway by either Shh protein or Glil overexpression abrogated the biological effects of TCRV. Taken together, the results of this study demonstrate that TCRV inhibits pancreatic cancer growth and EMT by targeting the Shh pathway and its downstream signaling mediators. TCRV inhibited EMT through the upregulation of miR-200 family members. Since TCRV effectively inhibited the growth of human pancreatic cancer cells by modulating the Shh pathway, without affecting the growth of HPNE cells, our findings suggest the possible use of TCRV as a promising candidate for the treatment and/or prevention of pancreatic cancer.

\section{Introduction}

Pancreatic ductal adenocarcinoma (PDAC) is currently the fourth leading cause of cancer-related mortality in the United States and is projected to become the second leading cause by 2030 (1). Pancreatic cancer is associated with a dismal prognosis, largely due to late disease presentation, aggressive local invasion with early metastatic spread and fairly resistant malignancy with a poor response to conventional chemotherapy and radiotherapy (2). An increased risk of pancreatic cancer has been associated with several environmental, biological and genetic factors. For example, exposure to certain classes of organic solvents, smoking, radiation, diabetes, chronic pancreatitis, prior gastric surgery and specific gene polymorphisms has been associated with the incidence of pancreatic cancer $(3,4)$. Despite a significant enhancement in our understanding of the genetic makeup of this disease and considerable advancements being made in the use of targeted therapy, the management of pancreatic cancer continues to be one of the greatest therapeutic challenges. Recent studies have documented the significance of dietary factors in the treatment and/or prevention of pancreatic cancer (5-12).

Resveratrol is a polyphenolic compound that is naturally found in many plant species (13). Due to several of its properties, such as anti-aging, anti-carcinogenic, anti-inflammatory and antioxidant properties, resveratrol is regarded as a beneficial 
agent for the treatment of chronic diseases and for increasing longevity in humans (14-17). In pre-clinical and animal models of pancreatic cancer, resveratrol has been shown to inhibit cell proliferation, metastasis and angiogenesis, and to induce apoptosis $(6,8,18,19)$. Furthermore, resveratrol sensitizes cancer cells and exerts synergistic effects with chemotherapy and radiotherapy to provide an enhanced advantage to conventional therapeutics $(14,20-22)$. Recent human clinical trials have demonstrated that resveratrol is safe and reasonably well-tolerated at doses of up to $5 \mathrm{~g}$ /day (23). However, the major limitation of its use in the management of human ailments is primarily due to its unfavorable pharmacokinetics (PK)/pharmacodynamics (PD) profile. This is in part due to its poor oral bioavailability; i.e., a low aqueous solubility and an extensive pre-systemic metabolism. Thus, in the present study, we used the resveratrol derivative, triacetyl-resveratrol (TCRV), which is more stable and provides a better PK/PD profile than parent resveratrol.

The hedgehog $(\mathrm{Hh})$ signaling pathway is highly conserved from Drosophila to humans. It plays a crucial role in embryonic development and cell fate decisions (24). The sonic hedgehog (Shh) canonical pathway is initiated by the binding of the Hh ligand to transmembrane receptor patched 1 (PTCH1), which relieves its repression on Smoothened (Smo), a G-protein coupled receptor. Thus, Smo activation leads to the transmission of the Hh signal through the protein complex, which results in nuclear translocation and in the activation of the glioma-associated oncogene homolog (Gli1), and in the degradation of the repressor form, Gli3 (25). Therefore, the activation of Shh signaling through Smo can either occur through the stimulation of Hh protein or the loss of PTCH1 activity. Upon the activation and translocation of Gli to the nucleus, Gli acts as a transcriptional regulator of its target genes and regulates the expression of Gli1, PTCH1, Bcl-2, Cyclin D1, Snail and vascular endothelial growth factor (VEGF) (26). Gli1 and Gli2 function as transcriptional activators, whereas Gli3 functions as a repressor (27). The Hh signaling pathway also plays a crucial role in adult tissue homeostasis (28). In adulthood, the Hh signaling pathway is usually repressed; however, its activity is maintained in certain stem cell populations to promote tissue renewal and regeneration. Several studies have implicated the aberrant activation of $\mathrm{Hh}$ signaling pathway in various human malignancies, such as medulloblastoma, rhabdomyosarcoma, hepatocellular carcinoma, pancreatic cancer, digestive tract cancer, colon cancer, breast cancer, small-cell lung carcinoma, basal cell carcinoma and prostate cancer (29-38). Furthermore, the transcriptional activation of Gli1/2 enhances cell proliferation and cell cycle progression, whereas the inhibition of Gli1/2 attenuates cell proliferation and induces apoptosis $(32,39,40)$.

MicroRNAs (miRNAs or miRs) are short noncoding RNAs that are evolutionarily conserved and can modulate gene expression at the post transcriptional level via sequence-specific interactions with the cognate mRNA targets (41). In mammalian cells, miRNAs regulate gene silencing through both degradations of the mRNA and inhibition of translation. Based on array data, miRNAs have been estimated to regulate $\sim 30 \%$ of the human genome (41). Various types of cancer, including pancreatic cancer have been identified to exhibit a deregulation of miRNA expression $(42,43)$. Indeed, a recent study identified that miRNAs can function as classical oncogenes or tumor suppressor genes (44). Furthermore, miRNAs can also regulate cancer progression and metastasis in various types of human cancer (45). More importantly, miRNA expression has been associated with the recurrence, development of metastases and/or the survival of patients through various clinical trials (45). miRNAs are significantly dysregulated in pancreatic cancer, suggesting the potential role of miRNAs as key regulators of pancreatic carcinogenesis. However, at least to the best of our knowledge, there are no studies available to date examining the effects of TCRV on epithelial-mesenchymal transition (EMT)-related miRNAs.

The aim of the present study was to elucidate the molecular mechanisms through which the resveratrol derivative, TCRV, inhibits the growth and EMT in pancreatic cancer cells and induces apoptosis. Our data demonstrate that TCRV inhibits the growth and induces the apoptosis of pancreatic cancer cells. TCRV inhibits EMT by the induction of E-cadherin expression and the inhibition of the expression of the EMT-associated transcription factors, Snail, Slug, and Zeb1 and N-cadherin. The inhibitory effects of TCRV on EMT are presumably exerted through the suppression of the Shh pathway and the upregulation of miR-200. These data indicated that TCRV may be used in the treatment and/or prevention of pancreatic cancer.

\section{Materials and methods}

Reagents and cell culture conditions. TCRV (trans-3,5,4'triacetylstilbene, 3,5,4'-Tri-O-acetyl resveratrol) was purchased from LKT Laboratories, Inc. (St. Paul, MN, USA). Recombinant human sonic hedgehog (Shh) protein was purchased from R\&D Systems (Minneapolis, MN, USA). Gli1 cDNA (pReceiver) was purchased from GeneCopoeia (Rockville, MD, USA). Plasmids expressing scrambled (Human pre-miRNA Scramble Negative Control Expression Lentivector, pCDH-CMVMCHEF1 $\alpha$-CopGFP), anti-miR-200a, b and c (MirZip ${ }^{\mathrm{TM}}$ anti-miRNA Expression Lentivector) and ZEB1 3'UTR construct (contains miR-200 family sites, MiR-Selection Fire-Ctx Lentivector) were purchased from System Biosciences (Palo Alto, CA, USA). The pancreatic cancer cells (AsPC-1 and PANC-1) and the human pancreatic normal ductal epithelial (HPNE) cells were purchased from the American Type Culture Collection (ATCC, Manassas, VA, USA). Dulbecco's modified Eagle's medium with $10 \%$ fetal bovine serum with antibiotics was used to grow the cancer cells. HPNE cells were grown as per the recommendations of ATCC.

Lentiviral particle production and transduction. Lentivirus was produced by the triple transfection of packaging 293T cells (American Type Culture Collection) with plasmid, lentiviral vector and lipofectamine 2000/Plus reagent, (Invitrogen/Thermo Fisher Scientific, Waltham, MA, USA) as per the manufacturer's instructions. Viral supernatants were collected and concentrated using PEG-it virus precipitation solution [System Biosciences (SBI)] by centrifugation $\left(1,500 \mathrm{x} \mathrm{g}\right.$ for $30 \mathrm{~min}$ at $\left.4^{\circ} \mathrm{C}\right)$ and concentrated 100 -fold to produce virus stocks with titers of $1 \times 10^{8}$ to $1 \times 10^{9}$ infectious units per $\mathrm{ml}$. Titers were determined on $293 \mathrm{~T}$ cells. The pancreatic cancer cells were transduced with lentiviral particles in the presence of $6 \mu \mathrm{g} / \mathrm{ml}$ polybrene (Thermo Fisher Scientific).

Apoptosis assay. Fluorescence-activated cell sorting (FACS) analysis was one of the methods used to determine cell 
apoptosis. In brief, the cultured cells were trypsinized, washed with PBS and resuspended in $200 \mu \mathrm{l}$ PBS and incubated with $10 \mu \mathrm{l}$ RNAase $(10 \mathrm{mg} / \mathrm{ml})$ at $37^{\circ} \mathrm{C}$. Following incubation of the cells for $30 \mathrm{~min}, 50 \mu \mathrm{l}$ propidium iodide solution was added, and tge induction of cell apoptosis was measured by flow cytometry (Accuri C6 flow cytometer; BD Biosciences, San Jose, CA, USA). The induction of apoptosis was further confirmed by another method using terminal deoxynucleotidyl transferase (TdT)-mediated dUTP nick-end labeling (TUNEL) and performed according to the manufacturer's instructions (Life Technologies, Grand Island, NY, USA).

Caspase- 3 activity assay. The cells ( $1 \times 10^{4}$ cells per well) were seeded in 96-well plates and treated with various concentrations of TCRV $(0-20 \mu \mathrm{M})$ for $36 \mathrm{~h}$. At the end of the incubation period, caspase-3 activity was measured using a colorimetric assay kit as per the manufacturer's instructions (Sigma-Aldrich, St. Louis, MO, USA). The caspase- 3 colorimetric assay kit was based on the hydrolysis of acetyl-Asp-Glu-Val-Asp p-nitroanilide (Ac-DEVD-pNA) by caspase-3, resulting in the release of the p-nitroaniline (pNA) moiety. The concentration of pNA released from the substrate was calculated from the absorbance values at $405 \mathrm{~nm}$ (BioTek Synergy Multimode Microplate reader; Thermo Fisher Scientific).

Colony formation assay. The cells (100 cells per well) were seeded in 6-well plates and treated with various concentrations of TCRV $(1,5,10$ and $20 \mu \mathrm{M})$. At the end of 21 days, colonies were fixed with $10 \%$ neutral-buffered formalin solution for $15-30 \mathrm{~min}$, and stained with crystal violet $(0.5 \%$ w/v; Sigma-Aldrich) at room temperature for $30 \mathrm{~min}$. The plates were washed with $\mathrm{dH}_{2} \mathrm{O}$ and allowed to dry. Colonies containing $>50$ individual cells were counted using a stereomicroscope (Olympus, New Orleans, LA, USA).

Transwell migration assay. Transwell migration assay was performed as previously described (46). In brief, non-coated membrane inserts (24-well insert; pore size, $8 \mu \mathrm{m}$; Corning Costar, Inc., New York, NY, USA) were used to plate $1 \times 10^{5}$ pancreatic cancer cells in the top chamber. The cells were then allowed to migrate towards the serum-containing DMED medium in the lower chamber. Following incubation for $24 \mathrm{~h}$, the cells that had migrated through the membrane were fixed with methanol for 15-30 min, and stained with $0.1 \%$ crystal violet (2 mg/ml; Sigma-Aldrich) at room temperature for $30 \mathrm{~min}$. The number of cells that migrated through the membrane were evaluated under a light microscope (Olympus) and counted.

Transwell invasion assay. Transwell invasion assay was performed as previously described (46). In brief, Matrigel (60 $\mu \mathrm{g}$; BD Biosciences) was freshly coated in the top chamber of the membrane inserts (24-well insert; pore size, $8 \mu \mathrm{m}$; Corning Costar, Inc.). A total of $1 \times 10^{5}$ pancreatic cancer cells in DMEM without serum or growth factors were plated in the top chamber before the invasion assay. In the lower chamber, DMEM supplemented with serum was used as a chemoattractant. Following incubation for $48 \mathrm{~h}$, the upper chamber was cleared up of non-invading cells using a cotton swab. The cells that had invaded on to the lower surface of the membrane were then fixed with methanol for 15-30 min, and stained with $0.1 \%$ crystal violet $(2 \mathrm{mg} / \mathrm{ml}$; Sigma-Aldrich) at room temperature for $30 \mathrm{~min}$. The number of cells that invaded through the membrane were evaluated under a light microscope (Olympus) and counted.

Motility assay. Scratch motility assay was used to monitor the horizontal movement of cells as previously described (46). The cells were seeded in a 6 -well plate to form a monolayer for $24 \mathrm{~h}$, and then a scratch was made using a pipette tip through the established monolayer giving rise to an in vitro wound. The cells were then washed twice with PBS, and wells were replaced with media with or without TCRV. Movement of cells from the confluent sides of the monolayer to the scratch area as single cells was monitored. They were viewed under a microscope in 4 separate areas each day until the width of the wound healing gap is filled in the untreated control wells. Three replicate wells from a 6-well plate were used for each experimental condition.

Reverse transcription-quantitative polymerase chain reaction $(R T-q P C R)$. Total RNA was isolated from the cultured cells using an RNeasy Mini kit (Qiagen, Valencia, CA, USA). Briefly, cDNA was synthesized by reverse transcription reaction using a high capacity cDNA reverse transcription kit (Applied Biosystems, Foster City, CA, USA). Signaling molecule specific primers used to generate the PCR products were designed using NCBI/Primer-BLAST (https://www.ncbi.nlm.nih. gov/tools/primer-blast). The gene amplification was quantified by qPCR using an ABI 7300 Sequence Detection System in the presence of SYBR-Green (Thermo Fisher Scientific). The following gene-specific primers were used: PTCH1 forward, 5'-TGA CCT AGT CAG GCT GGA AG-3' and reverse, 5'-GAA GGA GAT TAT CCC CCT GA-3'; Gli1 forward, 5'-CTG GAT CGG ATA GGT GGT CT-3' and reverse, 5'-CAG AGG TTG GGA GGT AAG GA-3'; Gli2 forward, 5'-GCC CTT CCT GAA AAG AAG AC-3' and reverse, 5'-CAT TGG AGA AAC AGG ATT GG-3'; Snail forward, 5'ACC CCA CAT CCT TCT CAC TG-3' and reverse, 5'-TAC AAA AAC CCA CGC AGA CA-3'; Zeb1 forward, 5'-GCA CAA CCA AGT GCA GAA GA-3' and reverse, 5'-CAT TTG CAG ATT GAG GCT GA-3'; E-cadherin forward, 5'-TGC TCT TGC TGT TTC TTC GG-3' and reverse, 5'-TGC CCC ATT CGT TCA AGT AG-3'; N-cadherin forward, 5'-TGG ATG GAC CTT ATG TTG CT-3' and reverse, 5'-AAC ACC TGT CTT GGG ATC AA-3'; GAPDH forward, 5'-GAG TCA ACG GAT TTG GTC GT-3' and reverse, 5'-TTG ATT TTG GAG GGA TCT CG-3'; Cyclin D1 forward, 5'-TTC AAA TGT GTG CAG AAG GA-3' and reverse, 5'-GGG ATG GTC TCC TTC ATC TT-3'; Bcl-2 forward, 5'-AGATGGGAACACTGGTGGAG-3' and reverse, 5'-CTTCCCCAAAAGAAATGCAA-3'; miR-200a forward, 5'-CAUCUUACCGGACAGUGCUGGA-3' and reverse, 5'-CATCTTACCGGACAGTGCTGGA-3'; miR-200b forward, 5'-CAUCUUACUGGGCAGCAUUGGA-3' and reverse, 5'-CATCTTACTGGGCAGCATTGG-3'; and miR200c forward, 5'-CCCTCGTCTTACCCAGCAGT-3 and reverse, 5'-CCATCATTACCCGGCAGTAT-3'.

Target sequences were amplified under the following reaction conditions: $95^{\circ} \mathrm{C}$ for $10 \mathrm{~min}$, followed by 40 cycles of $95^{\circ} \mathrm{C}$ for $15 \mathrm{sec}$ and $60^{\circ} \mathrm{C}$ for $1 \mathrm{~min}$. GAPDH was used as an endogenous normalization control. The experiments were performed in triplicate, and the results were calculated using 

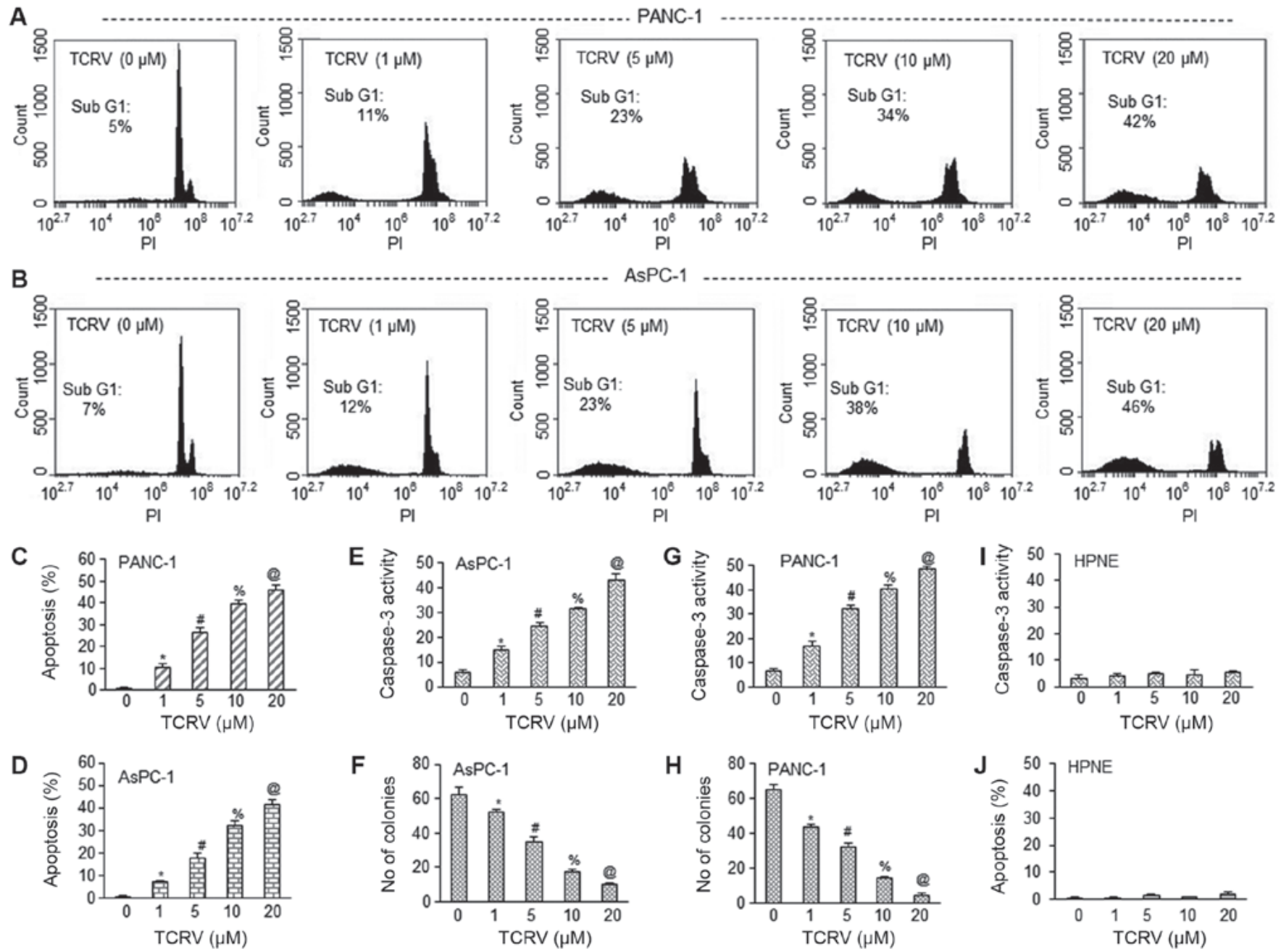

Figure 1. TCRV induces the apoptosis of, activates caspase-3 in and inhibits the colony formation of pancreatic cancer cells. (A-D) AsPC-1 and PANC-1 pancreatic cancer cells were treated with TCRV $(0-20 \mu \mathrm{M})$ for $48 \mathrm{~h}$, and apoptosis was measured. Data represent the means $\pm \mathrm{SD}(\mathrm{n}=4)$. The symbols *,\#,\% and @ indicate significant differences compared to the respective control $(\mathrm{P}<0.05)$. (E and G) AsPC-1 and PANC-1 pancreatic cancer cells were treated with TCRV $(0-20 \mu \mathrm{M})$ for $36 \mathrm{~h}$, and caspase-3 activity was measured as per the manufacturer's instructions (Sigma-Aldrich). Data represent the means $\pm \mathrm{SD}(\mathrm{n}=4)$. The symbols *,\#,\% and @ indicate significant differences compared to the respective control $(\mathrm{P}<0.05)$. (F and H) AsPC-1 and PANC-1 pancreatic cancer cells were treated with TCRV $(0-20 \mu \mathrm{M})$. After 3 weeks of treatment, colonies were fixed with $10 \%$ neutral-buffered formalin and stained with crystal violet. Colonies containing $>50$ individual cells were counted. Data represent the means $\pm \mathrm{SD}(\mathrm{n}=4)$. The symbols *,\#, \% and @ indicate significant differences compared to the respective control $(\mathrm{P}<0.05)$. (I and J) Human pancreatic normal ductal epithelial (HPNE) cells were treated with TCRV $(0-20 \mu \mathrm{M})$. Apoptosis and caspase-3 activity were measured for 48 and $36 \mathrm{~h}$, respectively. Data represent the means \pm SD $(n=4)$. TCRV, triacetyl resveratrol.

the $\Delta \Delta \mathrm{Ct}$ method. The $\mathrm{n}$-fold change in mRNA expression was determined according to the $2^{-\Delta \Delta C t}$ method (47).

Gli reporter assay. Gli reporter activity was measured as previously described (34). Briefly, the pancreatic cancer cells were transduced withlentivirus expressing luciferase reporterconstruct, and stable cells were selected. cop-GFP and luciferase genes were cloned downstream of Gli-response element, containing 4 Gli binding motifs (pGreen Fire1-4xGli-mCMV-EF1-Neo). The transduced pancreatic cancer cells (5-10,000 cells per well) were seeded in 12 -well plates for the transcription assay and treated with or without TCRV $(0-20 \mu \mathrm{M})$ for up to $48 \mathrm{~h}$. Following incubation, the cells were harvested and analyzed for either green fluorescence or luciferase reporter activity (Promega Corporation, Madison, WI, USA).

Statistical analysis. All results are presented as the means \pm SD that were calculated for each experimental group with replicates. ANOVA, followed by Bonferroni's multiple comparison tests using PRISM statistical analysis software (GraphPad Software, Inc., San Diego, CA, USA) was used to analyze the differences between groups. Statistically significant differences among groups were considered at $\mathrm{P}<0.05$.

\section{Results}

$T C R V$ induces the apoptosis and inhibits the colony formation of human pancreatic cancer cells, but has no effects on HPNE cells. We first measured the effects of TCRV on the apoptosis of, caspase-3 activity in and the colony formation of AsPC-1 and PANC-1 human pancreatic cancer cells (Fig. 1). Colony formation assay is regarded as a gold standard and is used to measure the effects of cytotoxic agents on the clonogenic survival of cancer cells in vitro. TCRV (1, 5,10 and $20 \mu \mathrm{M}$ ) induced apoptosis and caspase-3 activity, and inhibited the colony formation of both the AsPC-1 and 
A

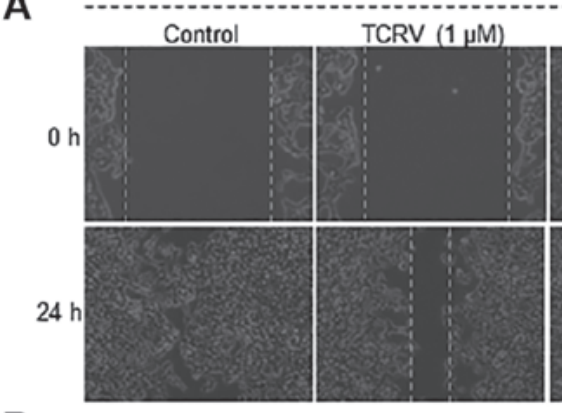

B
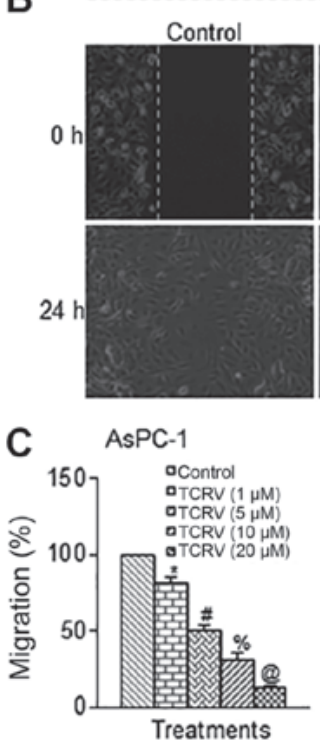

PANC-1

TCRV $(1 \mu \mathrm{M})$

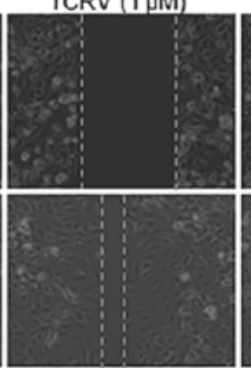
$\operatorname{TCRV}(5 \mu \mathrm{M})$

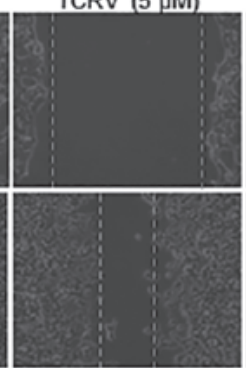

ASPC-1
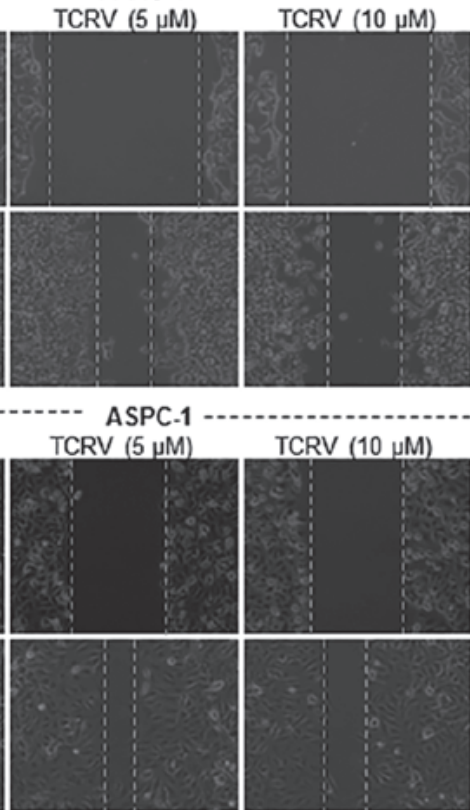

TCRV $(10 \mu \mathrm{M})$

D PANC-1

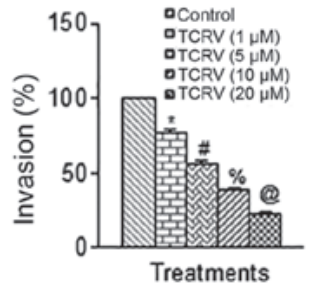

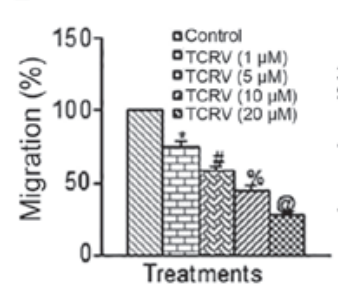

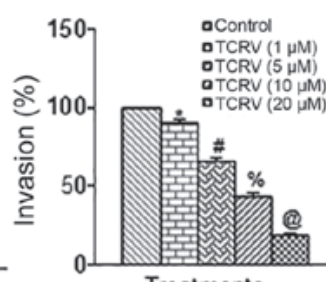

Treatments
E

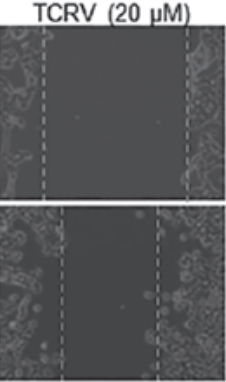

TCRV $(20 \mu \mathrm{M})$

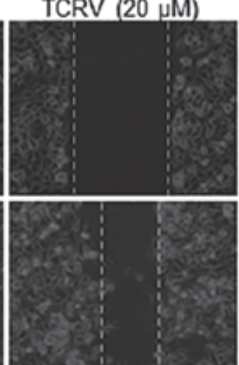

$\mathrm{H}$
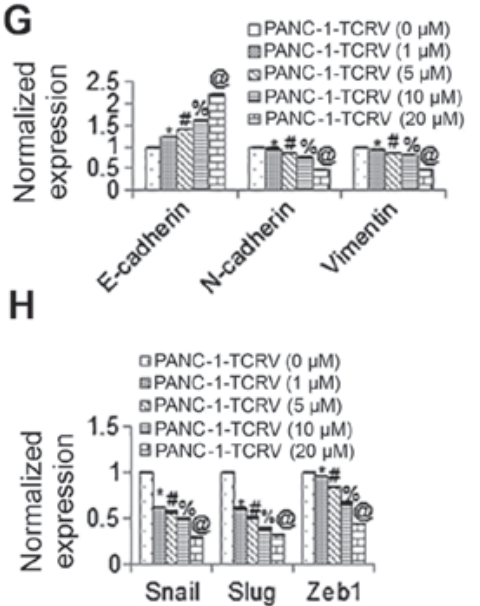

Figure 2. TCRV inhibits pancreatic cancer cell invasion and migration, and modulates the expression of genes related to epithelial-mesenchymal transition. (A and B) Motility assay. Photomicrographs demonstrating the results of the in vitro motility of AsPC-1 and PANC-1 cells after TCRV treatment. Pancreatic cancer cells were grown in monolayer, scratched and treated with or without TCRV for $48 \mathrm{~h}$. (C and D) Transwell migration assay. Pancreatic cancer cells were plated in the top chamber of the Transwell plate and treated with TCRV $(0-20 \mu \mathrm{M})$ for $24 \mathrm{~h}$. Cells that had migrated to the lower chambered were fixed with methanol, stained with crystal violet and counted. Matrigel invasion assay. AsPC-1 and PANC-1 cells were plated onto the Matrigel-coated membrane in the top chamber of the Transwell and treated with TCRV $(0-20 \mu \mathrm{M})$ for $48 \mathrm{~h}$. Cells that had invaded to the lower chambered were fixed with methanol, stained with crystal violet and counted. Data represent the means \pm SD $(n=4)$. The symbols *,\#, \% and @ indicate significant differences compared to the respective control $(\mathrm{P}<0.05)$. (E-H) Pancreatic cancer cells were treated with TCRV $(0-20 \mu \mathrm{M})$ for $36 \mathrm{~h}$. At the end of the incubation period, the expression of E-cadherin, $\mathrm{N}$-cadherin, Vimentin, Snail, Slug and Zeb1 was measured by RT-qPCR. Data represent the means \pm SD ( $\mathrm{n}=4$ ). The symbols *, \#, \% and @ indicate significant differences compared to the respective control $(\mathrm{P}<0.05)$. TCRV, triacetyl resveratrol.

PANC-1 cells in a dose-dependent manner (Fig. 1A-H). We selected these concentrations of TCRV based on our previously published studies on resveratrol in pancreatic cancer $(6,8,18,19)$. These data suggest that TCRV may be used as an anticancer agent.

We then examined the ability of TCRV to induce apoptosis and activate caspase-3 in HPNE cells. As shown in Fig. 1I-J, TCRV had no effect on apoptosis and caspase-3 activity in HPNE cells. Overall, our results demonstrated that TCRV induced apoptosis and inhibited the growth of AsPC-1 and PANC-pancreatic cancer 1 cells, but did not affect normal HPNE cells (Fig. 1I and J).

TCRV inhibits pancreatic cancer cell motility, migration and invasion. EMT an is essential process through which cancer cells to invade and migrate through the basement membrane. The EMT program is highly conserved and is implicated in the dissemination of primary epithelial cancer cells (48). Metastasis involves an increase in the motility and invasiveness of cancer cells. Metastatic cancer cells acquire motility by losing cell to cell adhesion, which is characterized by the loss of E-cadherin and an increase in the expression of its transcriptional repressors, Zeb1, Zeb2, Twist, Snail and Slug (49). In this study, we thus examined the effects of TCRV on the motility, migration and invasion of AsPC-1 and PANC-pancreatic cancer 1 cells. TCRV inhibited the motility, migration and invasion of both pancreatic cancer cell lines (Fig. 2-D). To examine the molecular mechanisms underlying the EMT process, we measured the expression of E-cadherin, $\mathrm{N}$-cadherin and Vimentin by RT-qPCR. TCRV enhanced the expression of E-cadherin and inhibited the expression of $\mathrm{N}$-cadherin and Vimentin in both the AsPC-1 and PANC-1 cell lines (Fig. 2E and G). These results thus suggest that the early metastasis of pancreatic cancer cells can be inhibited by TCRV through a 'cadherin switch' and the inhibition of Vimentin. Since the cell motility, migration and invasion of pancreatic cancer cells was inhibited by TCRV, we then examined the effects of TCRV on the regulation of the EMT-associated transcription factors, Snail, Slug and Zeb1 (Fig. 2F and H). The 
A

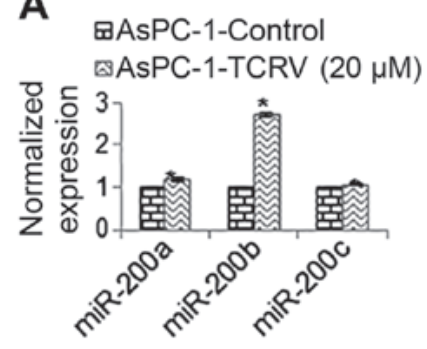

B

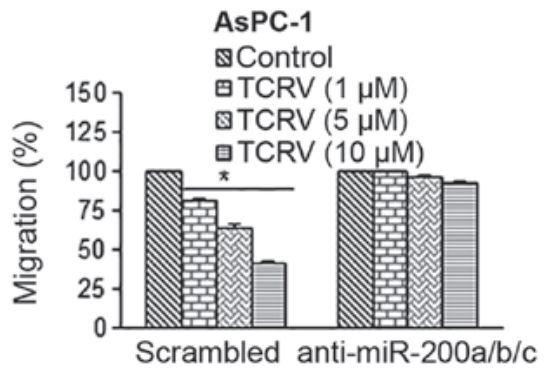

aANC-1-Control ब PANC-1-TCRV $(20 \mu \mathrm{M})$

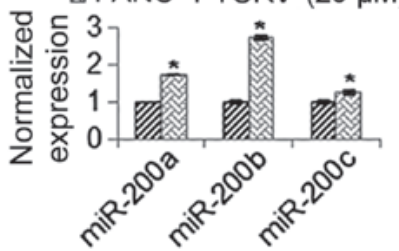

C AsPC-1
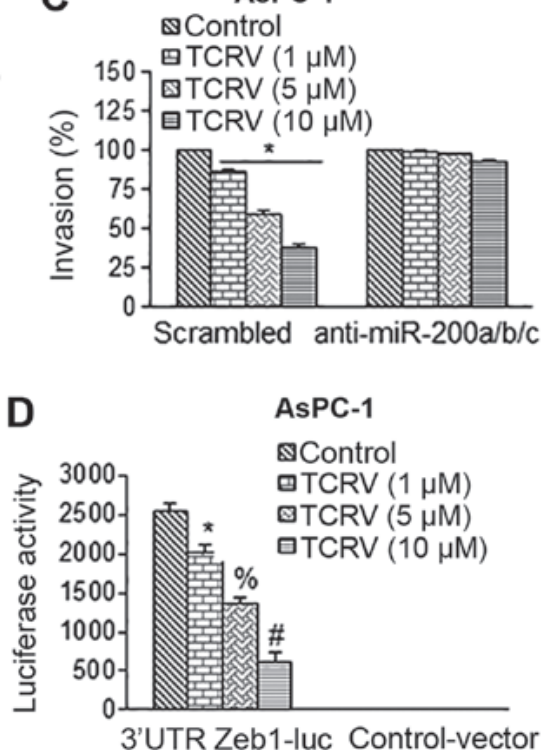

Figure 3. TCRV inhibits cell migration and invasion by upregulating miR-200 and inhibiting Zeb1. (A) AsPC-1 and PANC-1 cells pancreatic cancer were treated with TCRV $(10 \mu \mathrm{M})$ for $36 \mathrm{~h}$. At the end of the incubation period, RNA was extracted, and the expression of miR-200a, miR-200b and miR-200c was measured by RT-qPCR. Data represent the means $\pm \mathrm{SD}(\mathrm{n}=4)$. The symbol $*$ indicates a significant difference compared to the respective control $(\mathrm{P}<0.05)$. (B and C) AsPC-1 cells were transduced with scrambled, or anti-miR-200a, anti-miR-200b and anti-miR-200c lentiviral particles. Transduced cells were treated with TCRV $(0-10 \mu \mathrm{M})$ to measure cell migration and invasion for 24 and $48 \mathrm{~h}$, respectively. Data represent the mean $\pm \mathrm{SD}(\mathrm{n}=4)$. The symbol $*$ indicates a significant difference compared to the respective control $(\mathrm{P}<0.05)$. (D) TCRV inhibits 3'UTR Zeb1 luciferase reporter activity. AsPC-1 cells were transduced with either 3'UTR-Zeb1 luciferase reporter construct or control vector. Following transduction, the cells were treated with TCRV (0-10 $\mu \mathrm{M})$ for 36 h, and Zeb1 reporter activity was measured. Data represent the means \pm SD $(n=4)$. The symbols *,\# and \% indicate significant differences compared to the respective control $(\mathrm{P}<0.05)$. TCRV, triacetyl resveratrol.

RT-qPCR data indicated that TCRV inhibited the expression of the EMT factors, Snail, Slug and Zeb1. Taken together, these data suggest that TCRV modulates the expression of cadherins, Vimentin, and that of the EMT transcription factors, Snail, Slug and Zeb1, and can thus can regulate the early metastasis of pancreatic cancer.

TCRV inhibits EMT through the modulation of miR-200 and Zebl in pancreatic cancer. In defining the underlying molecular mechanisms of action of TCRV, we further explored the involvement of miRNAs that can regulate the gene expression of target mRNAs through either their degradation or the repression of translation. It has been shown that miR-200 inhibits the expression of Zeb1 by directly targeting the 3'UTR's of Zeb1 mRNA (50). In this study, we found that the loss of Zeb1 expression due to the miR-200-mediated downregulation of Zeb1 was associated with a significant reduction in the invasive phenotype of cancer cells. The binding sites of miR-200a, miR-200b, and miR-200c on the 3'UTR of Zeb1 were identified (data not shown). To examine the role of the miR-200 family in the regulation of EMT, we thus measured the expression of miR-200 family members (Fig. 3A). TCRV induced the expression of miR-200a, miR-200b and miR-200c in the AsPC-1 cells. We thus hypothesized that if the miR-200 family mediates the effects of TCRV, then the inhibition of miR-200 should abolish the biological effects of TCRV. The overexpression of anti-miR-200a/b/c in the AsPC-1 cells counteracted the inhibitory effects of TCRV on cell migration and invasion (Fig. 3B and C).

Since miR-200 transcriptionally targets Zeb1, we further evaluated the 3'UTR Zeb1-luciferase activity in the AsPC-1 cells upon treatment with TCRV (Fig. 3D). In the AsPC-1 cells treated with TCRV, the 3'UTR Zeb1-luciferase activity was inhibited. By comparison, the cells transduced with the control vector (with no miR-200 binding sites) had no luciferase activity. These data suggest that TCRV inhibits Zeb1 through miR-200 family members.

TCRV inhibits the transcriptional activity of Gli and its downstream targets in pancreatic cancer cells. We then examined the effect of TCRV on the Shh-Gli pathway. To this end, the effects of TCRV on Gli transcriptional activity were evaluated using a reporter assay. A Gli-dependent luciferase reporter construct was used to transduce the AsPC-1 and PANC-1 cells followed by treatment with TCRV for $36 \mathrm{~h}$. As shown in Fig. 4A and D, the Gli transcriptional activity was inhibited in both the AsPC-1 and PANC-1 cells in a dose-dependent manner upon treatment with TCRV. These data suggest that the pro-apoptotic activities of TCRV are exerted through the inhibition of the Shh pathway.

We then measured the effects of TCRV on the expression of Gli target genes in AsPC-1 and PANC-1 cells by RT-qPCR. TCRV inhibited the expression of Bcl-2 and Cyclin D1 in the AsPC-1 and PANC-1 cells (Fig. 4B and E). Similarly, TCRV inhibited the gene expression levels of Gli effectors (Gli1 and Gli2) and the receptor (PTCH1) of the Shh pathway in both cell lines (Fig. 4C and F). Taken together, these results suggest that TCRV suppresses the Shh pathway and its target genes to regulate pancreatic cancer cell growth.

The inhibitory effects of TCRV on apoptosis and the epithelial-mesenchymal transition are mediated by 

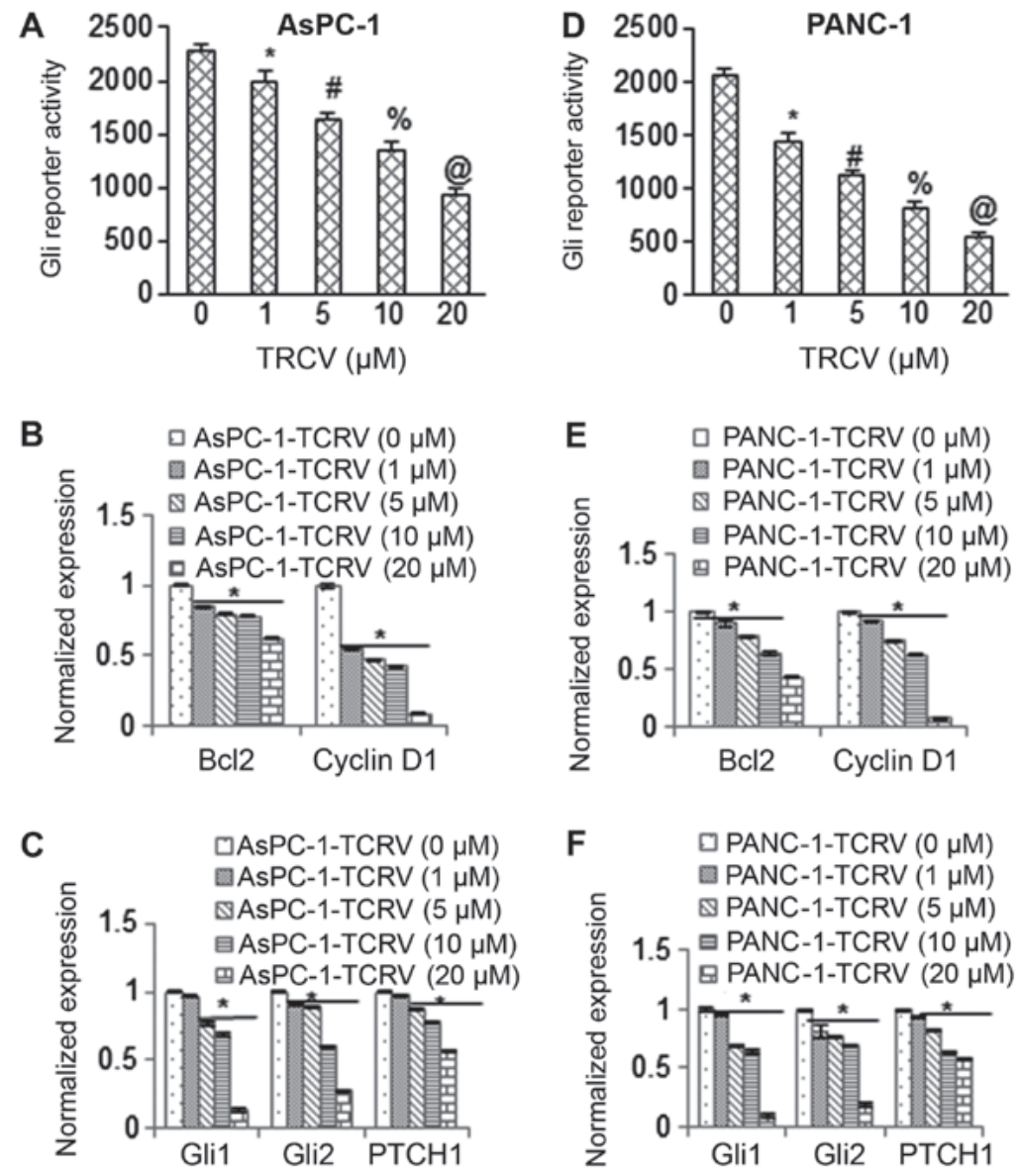

Figure 4. TCRV inhibits Gli reporter activity and Gli target genes. (A) Inhibition of Gli reporter activity in AsPC-1 pancreatic cancer cells by TCRV. AsPC-1 cells were transduced with lentiviral particles expression Gli reporter construct and treated with TCRV $(0-20 \mu \mathrm{M})$ for $36 \mathrm{~h}$, and Gli reporter activity was measured. Data represent the means \pm SD $(\mathrm{n}=4)$. The symbols *,\#,\% and @ indicate significant differences compared to the respective control $(\mathrm{P}<0.05)$. (B and C) AsPC-1 cells were treated with TCRV $(0-20 \mu \mathrm{M})$ for $36 \mathrm{~h}$. At the end of the incubation period, the expression of Bcl-2, cyclin D1, Gli1, Gli2 and Patched1 (PTCH1) was measured by RT-qPCR. Data represent the means \pm SD $(n=4)$. The symbol $*$ indicates a significant difference compared to the respective control $(\mathrm{P}<0.05)$. (D) Inhibition of Gli reporter activity in PANC-1 cells by TCRV. PANC-1 cells were transduced with lentiviral particles expressing Gli reporter and treated with TCRV $(0-10 \mu \mathrm{M})$ for $36 \mathrm{~h}$, and reporter activity was measured. Data represent the means $\pm \mathrm{SD}(\mathrm{n}=4)$. The symbols *,\#,\% and @ indicate significant differences compared to the respective control $(\mathrm{P}<0.05)$. (E and F) PANC-1 cells were treated with TCRV $(0-20 \mu \mathrm{M})$ for $36 \mathrm{~h}$. At the end of the incubation period, the expression of Bcl-2, cyclin D1, Gli1, Gli2 and PTCH1 was measured by RT-qPCR. Data represent the means \pm SD ( $=4)$. The symbol * indicates a significant difference compared to the respective control $(\mathrm{P}<0.05)$. TCRV, triacetyl resveratrol.

modulation of Sonic hedgehog pathway. To further confirm the role of the Shh pathway in mediating the effects of TCRV on apoptosis, invasion and migration, we took a dual approach. Firstly, we used the Shh protein to activate the Shh pathway (Fig. 5). To this end, we pretreated the AsPC-1 cells with Shh protein $(100 \mathrm{nM})$ for $2 \mathrm{~h}$, followed by treatment with TCRV $(0-20 \mu \mathrm{M})$ for $36-48 \mathrm{~h}$ to measure apoptosis, invasion and migration. As shown in Fig. 5A-C, TCRV induced the apoptosis, and inhibited invasion and migration of AsPC-1 cells. Pretreatment of the cells with Shh protein abolished the effects of TCRV on apoptosis, invasion and migration. Since Shh protein induces Gli transcription, we further evaluated the effects of Shh pathway activation on the Gli reporter activity (Fig. 5D). Treatment with TCRV $(0-20 \mu \mathrm{M})$ inhibited Gli reporter activity in the AsPC-1 cells in a dose-dependent manner. Furthermore, pretreatment of the AsPC-1 cells with Shh protein abolished the inhibitory effects of TCRV on Gli reporter activity. Therefore, these data suggest the role of the Shh-Gli pathway in mediating the biological effects of TCRV.

In the second approach, we hyperactivated the Shh pathway by overexpressing Gli1 (Fig. 6). Either empty vector or Glil cDNA was used to transduce AsPC-1 cells followed by treatment with various doses of TCRV (0-20 $\mu \mathrm{M})$. TCRV induced the apoptosis, and inhibited the invasion and migration of AsPC-1 cells transduced with empty vector (Fig. 6A-C). By contrast, the overexpression of Gli with Gli1 cDNA resulted in the inhibition of TCRV-induced apoptosis, and further abrogated the effects of TCRV on the invasion and migration of AsPC-1 cells. We then examined the influence of Shh pathway activation by Gli1 overexpression on the inhibitory effects of TCRV on Gli reporter activity. As shown in Fig. 6D, the results suggested that TCRV indeed inhibited Gli reporter activity in AsPC-1/vector cells. However, the overexpression of Gli1 abolished the inhibitory effects of TCRV on Gli reporter activity in AsPC-1/Gli1 cells. These data confirm our findings that the Shh-Gli pathway is required for the anti-metastatic and pro-apoptotic effects of TCRV on pancreatic cancer cells.

\section{Discussion}

In the current study, to the best of our knowledge, we demonstrate for the first time that TCRV inhibits pancreatic 

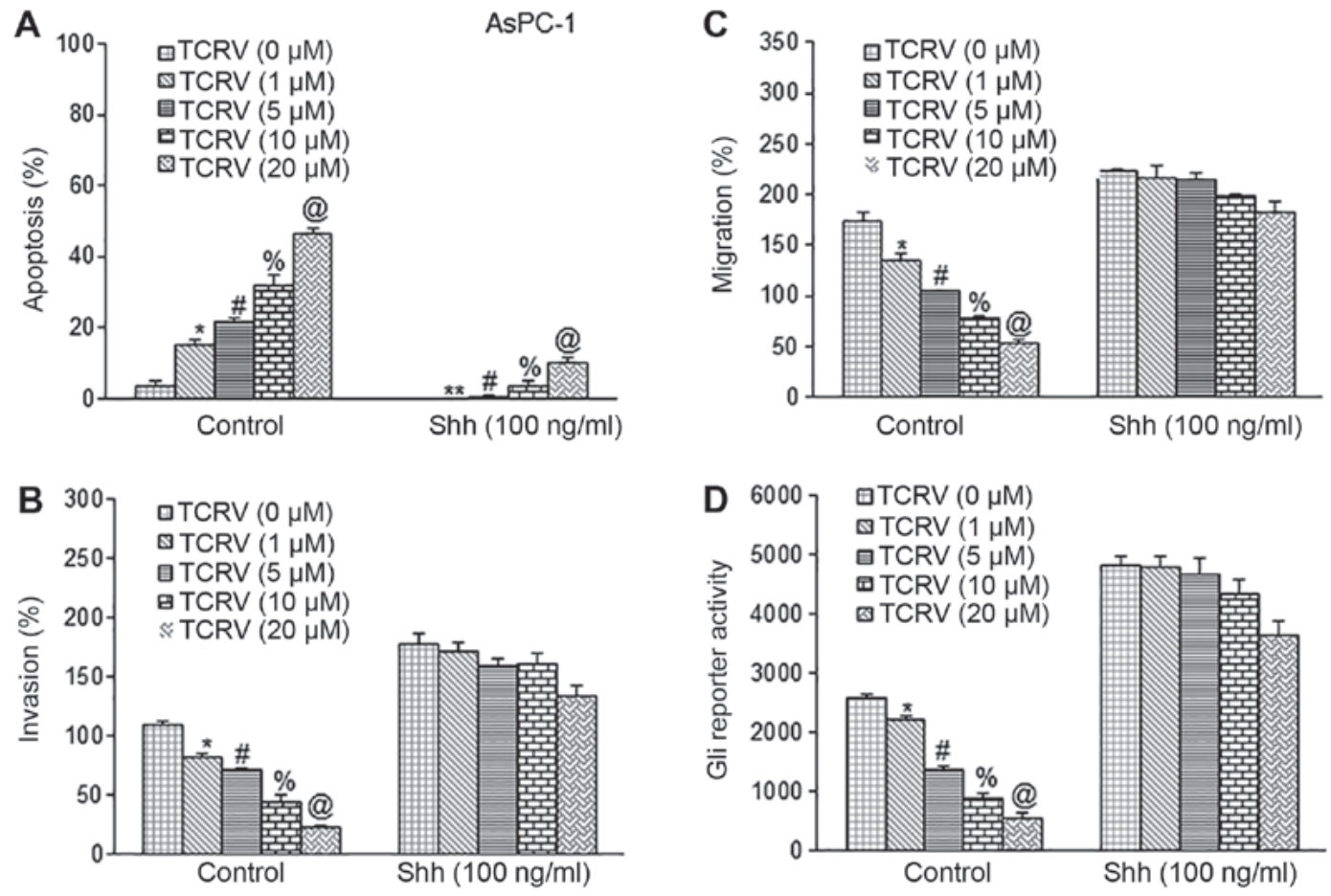

Figure 5. Sonic hedgehog protein counteracts the biological effects of TCRV. (A) AsPC-1 cells were pretreated with Shh protein (100 nM) for $2 \mathrm{~h}$ followed by TCRV $(0-20 \mu \mathrm{M})$ for $48 \mathrm{~h}$. At the end of the incubation period, apoptosis was measured by TUNEL assay. Data represent the means \pm SD. The symbols*,\#,\% and @ indicate significant differences compared to the respective control $(\mathrm{P}<0.05)$. (B) Matrigel invasion assay. AsPC-1 cells were pretreated with Shh protein $(100 \mathrm{nM})$ for $2 \mathrm{~h}$ followed by TCRV $(0-20 \mu \mathrm{M})$ for $48 \mathrm{~h}$. At the end of the incubation period, cell invasion was measured as described in Material and methods. Data represent the means \pm SD $(\mathrm{n}=4)$. The symbols *,\#,\% and @ indicate significant differences compared to the respective control $(\mathrm{P}<0.05)$. (C) Transwell migration assay. AsPC-1 cells were pretreated with Shh protein $(100 \mathrm{nM})$ for $2 \mathrm{~h}$ followed by TCRV $(0-20 \mu \mathrm{M})$ for $48 \mathrm{~h}$. At the end of the incubation period, cell migration was measured as described in the Material and methods. Data represent the means \pm SD ( $\mathrm{n}=4)$. The symbols *,\#, \% and @ indicate significant differences compared to the respective control $(\mathrm{P}<0.05)$. (D) Shh counteracts the inhibitory effects of TCRV on Gli reporter activity. AsPC-1 cells were transduced with lentiviral particles expressing Gli reporter construct. Transduced cells were pretreated with Shh protein (100 nM) for $2 \mathrm{~h}$, followed by TCRV $(0-20 \mu \mathrm{M})$ for $48 \mathrm{~h}$. At the end of the incubation period, Gli reporter activity was measured. Data represent the means $\pm \mathrm{SD}(\mathrm{n}=4)$. The symbols *,\#,\% and @ indicate significant differences compared to the respective control $(\mathrm{P}<0.05)$. TCRV, triacetyl resveratrol.

cancer growth by inducing the apoptosis of, and inhibiting the colony formation and EMT in pancreatic cancer cells, whereas it has no effect on HPNE cells. TCRV modulated the cadherin switch and inhibits EMT by downregulating the EMT-associated transcription factors, Snail, Slug and Zeb1. Furthermore, the upregulation of the miR-200 family by TCRV inhibited Zeb1 transcriptional activity and pancreatic cancer cell invasion and migration. Finally, the biological effects of TCRV on apoptosis and EMT were found to be regulated via the inhibition of the Shh pathway and its target genes.

Resveratrol is a naturally occurring polyphenolic compound with a wide spectrum of beneficial biological activities in human health by acting as an antioxidant, neuroprotector, cardioprotector and anticancer agent (13). TCRV is derived from resveratrol by esterase activity and exhibits better bioactivity than resveratrol in cell culture models. The therapeutic properties of TCRV are superior to those of resveratrol due to the following reasons: i) It is much more lipid-soluble and absorbs lipid membranes at a much more rapid rate; ii) it decreases exposure to the enzymes responsible for glucuronidation and sulfation; iii) its acetyl groups resist breakdown better than hydroxy groups; and iv) its acetyl groups enhance binding with proteins/substrates $(51,52)$. Based on these biochemical properties, TCRV is an attractive and effective candidate for the treatment and prevention of pancreatic cancer.
In the majority of cancers, aberrant Hh pathway activation is associated with poor treatment outcomes or the development of chemoresistance. The deregulation of the Shh pathway has been associated with the mutation of the Kras oncogene and has been shown to be an early event in pancreatic carcinogenesis (53-55). Furthermore, hedgehog signaling plays a functional role in the tumor microenvironment by regulating myofibroblast differentiation and inducing the stroma-derived growth-promoting molecules (56). Human pancreatic adenocarcinoma is characterized by precursor lesions (PanIN) which contain multiple genetic mutations among which activating K-ras mutations and the overexpression in HER-2/neu along with the aberrant expression of Shh have been demonstrated to occur early in progression. In Pdx-Shh mice, the pancreata have been shown to develop abnormal tubular structures, PanIN-1 and -2 (57). We have recently demonstrated that the aberrant activation of the Shh pathway components is expressed in human pancreatic cancer stem cells and pancreatic cancer cell lines, which could be inhibited by various chemopreventive agents such as sulforaphane, resveratrol and EGCG $(5,8,33,58,59)$. It is thus imperative from these data that the activation of Shh signaling is an early event and the maintenance of Shh signaling plays a critical role in pancreatic cancer proliferation and progression.

Metastasis is a leading cause of cancer-related mortality which involves the degradation of the extracellular matrix and 

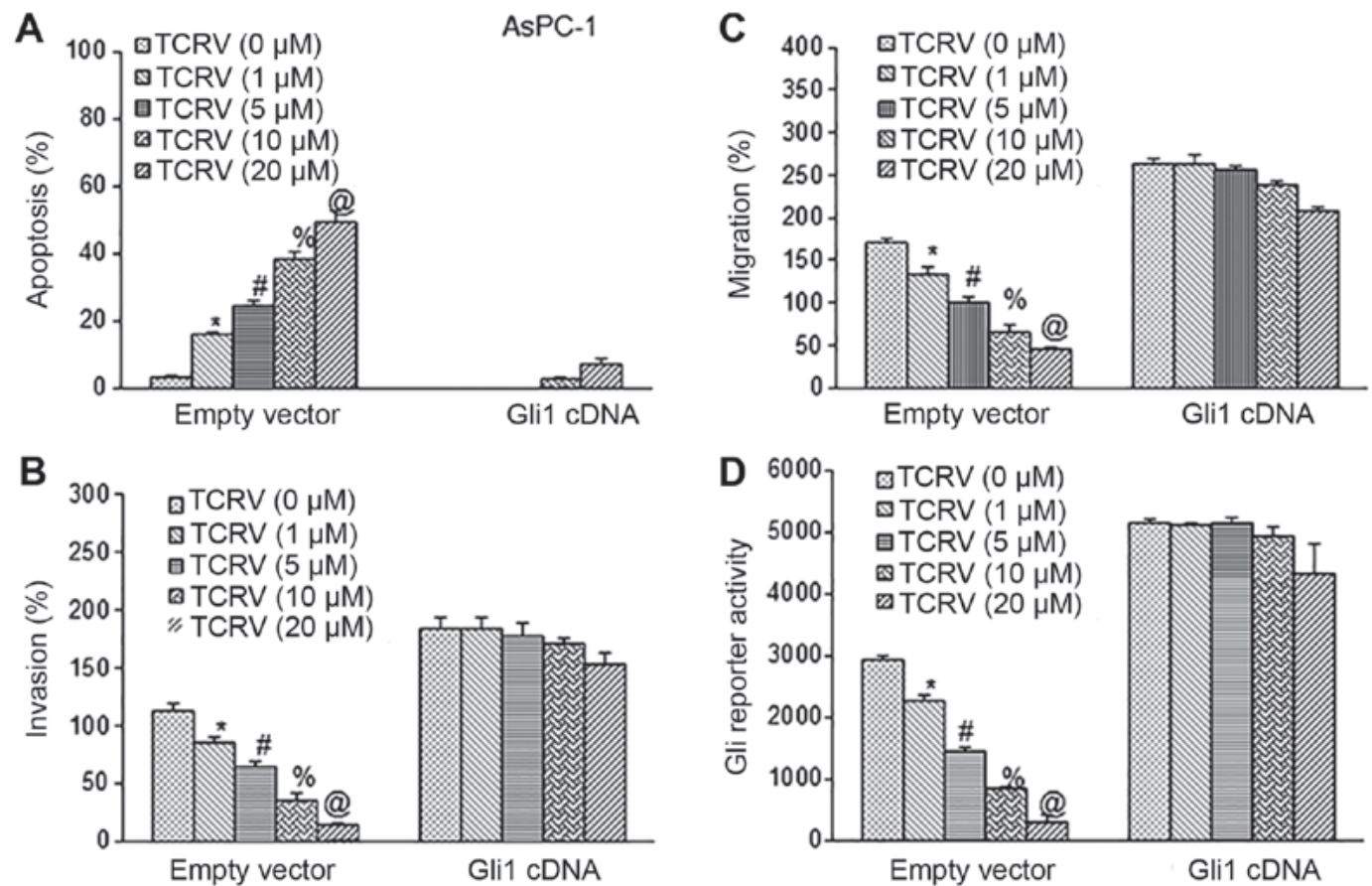

Figure 6. Overexpression of Gli counteracts the biological effects of TCRV. (A) AsPC-1 cells were transiently transfected with either empty vector or Gli1 cDNA, and treated with TCRV $(0-20 \mu \mathrm{M})$ for $48 \mathrm{~h}$. At the end of the incubation period, apoptosis was measured by TUNEL assay. Data represent the means $\pm \mathrm{SD}(\mathrm{n}=4)$. The symbols *,\#, \% and @ indicate significant differences compared to the respective control $(\mathrm{P}<0.05)$. (B) Matrigel invasion assay. AsPC-1 cells were transiently transfected with either empty vector or Glil cDNA, and treated with TCRV $(0-20 \mu \mathrm{M})$ for $48 \mathrm{~h}$. At the end of the incubation period, cell invasion was measured. Data represent the means \pm SD $(n=4)$. The symbols *,\#, \% and @ indicate significant differences compared to the respective control $(\mathrm{P}<0.05)$. (C) Transwell migration assay. AsPC-1 cells were transiently transfected with either empty vector or Gli1 cDNA and treated with TCRV $(0-20 \mu \mathrm{M})$ for $48 \mathrm{~h}$. At the end of the incubation period, cell migration was measured. Data represent the means $\pm \mathrm{SD}(\mathrm{n}=4)$. The symbols *, \#, \% and @ indicate significant differences compared to the respective control $(\mathrm{P}<0.05)$. (D) Gli1 counteracts the inhibitory effects of TCRV on Gli reporter activity. AsPC-1 cells were co-transfected with either empty vector or Gli1 cDNA along with Gli-luciferase reporter construct. Cells were treated with TCRV $(0-20 \mu \mathrm{M})$ for $48 \mathrm{~h}$ At the end of the incubation period, Gli reporter activity was measured. Data represent the means \pm SD $(n=4)$. The symbols *,\#, \% and @ indicate significant differences compared to the respective control $(\mathrm{P}<0.05)$. TCRV, triacetyl resveratrol.

the invasion of the local and distant tissues by cancer cells (2). The most critical step in invasion and metastases is attributed to the process of EMT, in which transformed sessile epithelial cells acquire a motile mesenchymal phenotype characterized by cadherin switch, loss of homotypic adhesion and cell polarity. Thus, the dissemination of cells from the primary tumor followed by their re-establishment in a secondary site is required for sustained metastatic growth, and EMT confers a metastatic ability on carcinoma. In the present study, TCRV induced apoptosis and inhibited EMT in pancreatic cancer cells. This may be due to the heterogeneous characteristics of the cell population; i.e., some cells are likely to be sensitive to apoptosis, while other surviving cells may undergo EMT. Since TCRV induced apoptosis, it may have affected cell migration and EMT characteristics. Furthermore, growth arrest in response to TCRV treatment may lead to apoptosis.

Zeb1 and Zeb2 overexpression in several primary tumors have been significantly associated with a poorer prognosis and have been inversely correlated with E-cadherin (60). Thus, EMT-associated transcription factors and regulators Snail, Slug, SNAI3, Zeb1, Zeb2, KLF8 and Twist1/2 repress CDH1 gene encoding E-cadherin. In the present study, we demonstrated a key and essential role of the Shh-Gli pathway in the promotion of pancreatic cancer metastasis. We demonstrated that TCRV suppressed cell motility, invasion and migration through the inhibition of EMT. TCRV significantly inhibited the expression of the EMT-associated transcription factors Zeb1, Snail and Slug. Additionally, the depletion of EMT regulators decreased the expression of $\mathrm{N}$-Cadherin and Vimentin and further increased the expression level of E-Cadherin in pancreatic cancer cells, suggesting a potential beneficial role of TCRV in early metastasis. Our gene expression analyses were based on mRNA levels. We did not measure protein expression by western blot analysis, which may be considered a limitation of this study. Nevertheless, the mRNA levels on EMT-related genes has been shown to correspond with the protein expression in our other study (11).

During metastasis, cancer cells acquire multiple molecular traits to counteract anoikis, migrate, invade, proliferate and survive in distant/unrelated microenvironments (61). Several studies have highlighted that miRNAs play a significant role in the regulation of metastasis (62-64). In the current study, we demonstrated that TCRV inhibited EMT in pancreatic cancer cells via the upregulation of miR-200a, miR-200b, and miR-200c, and the inhibition of Zeb1 expression. In support of our study, the role of miR200 in regulation of EMT has been demonstrated (65). Furthermore, miR-200 does not play any role in cell death or apoptosis. For this reason, we did not measure apoptosis under conditions of miR-200 knockdown. In this study, TCRV induced apoptosis through the activation of caspase-3. Furthermore, Zeb1 has been shown to be a direct target of miR-200 family members (50). Zeb1 links EMT activation and stemness maintenance and this regulates tumorigenesis. Furthermore, since the loss of miR-200 
expression is a late event in the progression of pancreatic cancer, it can be concluded that it may be relevant to the development of distant metastases. Thus, our study indicates that targeting the Zeb1-miR-200 feedback loop may provide the basis for a potential treatment strategy for pancreatic cancer.

The ability of TCRV to inhibit the Shh-Gli pathway was confirmed by two approaches; i.e., the use of Shh protein and the overexpression of by transfection with Gli1 cDNA. Using both the approaches, the hyperactivation of the Shh pathway counteracted the inhibitory effects of TCRV on apoptosis, cell migration and invasion. This study confirmed that the Shh pathway was involved in mediating the biological effects of TCRV. Similarly, we have recently demonstrated that resveratrol suppressed the pluripotency maintaining factors (Nanog, Sox-2, c-Myc and Oct-4) to mediate the inhibition of the self-renewal capacity of pancreatic cancer stem cells (8). Moreover, the ability of resveratrol to attenuate the self-renewal capacity of pancreatic cancer stem cells was further enhanced by the inhibition of Nanog by RNAi (8). Further studies are required to demonstrate the exact role of TCRV in human pancreatic cancer.

In conclusion, we in this study, we demonstrated that TCRV selectively inhibited human pancreatic cancer growth by inducing apoptosis without having any negative impact on HPNE cells, and this is suggestive of its potential use in the treatment and/or prevention of pancreatic cancer. Furthermore, we demonstrated that TCRV inhibited pancreatic cancer cell invasion and migration by upregulating the miR-200 family and inhibiting the transcription and expression of Zeb1. The biological effects of TCRV were exerted through the inhibition of the Shh pathway. Since the activation of the Shh pathway is associated with pancreatic malignancy, TCRV alone or in combination with standard chemotherapeutic or targeted drugs effecting tumor microenvironment may be tested in clinical trials for the management of pancreatic cancer in the future.

\section{Acknowledgements}

The authors would like to thank the laboratory members for the critical reading of the manuscript.

\section{Funding}

No funding was received.

\section{Availability of data and materials}

All data generated or analyzed during this study are included in this published article or are available from the corresponding author on reasonable request.

\section{Authors' contributions}

JF performed the experiments, analyzed the data and wrote the manuscript. SS, AS, SKS and RKS designed the study, contributed the reagents and/or provided scientific inputs. All authors have read and approved the final manuscript.

\section{Ethics approval and consent to participate}

Not applicable.

\section{Patient consent for publication}

Not applicable.

\section{Competing interests}

The authors declare that no competing interests exist.

\section{References}

1. Siegel R, Naishadham D and Jemal A: Cancer statistics, 2013. CA Cancer J Clin 63: 11-30, 2013.

2. Hidalgo M: Pancreatic cancer. N Engl J Med 362: 1605-1617, 2010.

3. Li D: Molecular epidemiology of pancreatic cancer. Cancer J 7: 259-265, 2001

4. Gold EB and Goldin SB: Epidemiology of and risk factors for pancreatic cancer. Surg Oncol Clin N Am 7: 67-91, 1998.

5. Li SH, Fu J, Watkins DN, Srivastava RK and Shankar S: Sulforaphane regulates self-renewal of pancreatic cancer stem cells through the modulation of Sonic hedgehog-GLI pathway. Mol Cell Biochem 373: 217-227, 2013.

6. Roy SK, Chen Q, Fu J, Shankar S and Srivastava RK: Resveratrol inhibits growth of orthotopic pancreatic tumors through activation of FOXO transcription factors. PLoS One 6: e25166, 2011.

7. Shankar S, Ganapathy S, Hingorani SR and Srivastava RK: EGCG inhibits growth, invasion, angiogenesis and metastasis of pancreatic cancer. Front Biosci 13: 440-452, 2008.

8. Shankar S, Nall D, Tang SN, Meeker D, Passarini J, Sharma J and Srivastava RK: Resveratrol inhibits pancreatic cancer stem cell characteristics in human and KrasG12D transgenic mice by inhibiting pluripotency maintaining factors and epithelial-mesenchymal transition. PLoS One 6: e16530, 2011.

9. Shankar S, Suthakar G and Srivastava RK: Epigallocatechin-3gallate inhibits cell cycle and induces apoptosis in pancreatic cancer. Front Biosci 12: 5039-5051, 2007.

10. Srivastava RK, Tang SN, Zhu W, Meeker D and Shankar S: Sulforaphane inhibits self-renewal capacity of pancreatic cancer stem cells and synergizes with quercetin. Front Biosci (Elite Ed) 3: 515-528, 2011.

11. Verma RK, Yu W, Shrivastava A, Shankar S and Srivastava RK: $\alpha$-Mangostin-encapsulated PLGA nanoparticles inhibit pancreatic carcinogenesis by targeting cancer stem cells in human, and transgenic (Kras(G12D), and Kras(G12D)/tp53R270H) mice. Sci Rep 6: 32743, 2016.

12. Zhao M, Tang SN, Marsh JL, Shankar S and Srivastava RK: Ellagic acid inhibits human pancreatic cancer growth in Balb c nude mice. Cancer Lett 337: 210-217, 2013.

13. Shankar S, Singh G and Srivastava RK: Chemoprevention by resveratrol: Molecular mechanisms and therapeutic potential. Front Biosci 12: 4839-4854, 2007.

14. Shankar S, Siddiqui I and Srivastava RK: Molecular mechanisms of resveratrol (3,4,5-trihydroxy-trans-stilbene) and its interaction with TNF-related apoptosis inducing ligand (TRAIL) in androgen-insensitive prostate cancer cells. Mol Cell Biochem 304: 273-285, 2007.

15. Jang M and Pezzuto JM: Cancer chemopreventive activity of resveratrol. Drugs Exp Clin Res 25: 65-77, 1999.

16. Marques FZ, Markus MA and Morris BJ: The molecular basis of longevity, and clinical implications. Maturitas 65: 87-91, 2010.

17. Marzetti E, Wohlgemuth SE, Anton SD, Bernabei R, Carter CS and Leeuwenburgh C: Cellular mechanisms of cardioprotection by calorie restriction: state of the science and future perspectives. Clin Geriatr Med 25: 715-732, 2009

18. Harikumar KB, Kunnumakkara AB, Sethi G, Diagaradjane P, Anand P, Pandey MK, Gelovani J, Krishnan S, Guha S and Aggarwal BB: Resveratrol, a multitargeted agent, can enhance antitumor activity of gemcitabine in vitro and in orthotopic mouse model of human pancreatic cancer. Int J Cancer 127: 257-268, 2010.

19. Oi N, Jeong CH, Nadas J, Cho YY, Pugliese A, Bode AM and Dong Z: Resveratrol, a red wine polyphenol, suppresses pancreatic cancer by inhibiting leukotriene $\mathrm{A}_{4}$ hydrolase. Cancer Res 70: 9755-9764, 2010.

20. Shankar S, Chen Q, Siddiqui I, Sarva K and Srivastava RK: Sensitization of TRAIL-resistant LNCaP cells by resveratrol (3,4',5-tri-hydroxystilbene): Molecular mechanisms and therapeutic potential. J Mol Signal 2: 7, 2007. 
21. Delmas D, Jannin B and Latruffe N: Resveratrol: Preventing properties against vascular alterations and ageing. Mol Nutr Food Res 49: 377-395, 2005.

22. Fulda S and Debatin KM: Resveratrol-mediated sensitisation to TRAIL-induced apoptosis depends on death receptor and mitochondrial signalling. Eur J Cancer 41: 786-798, 2005.

23. Patel KR, Scott E, Brown VA, Gescher AJ, Steward WP and Brown K: Clinical trials of resveratrol. Ann N Y Acad Sci 1215: 161-169, 2011.

24. Saqui-Salces $M$ and Merchant JL: Hedgehog signaling and gastrointestinal cancer. Biochim Biophys Acta 1803: 786-795, 2010.

25. Kinzler KW, Ruppert JM, Bigner SH and Vogelstein B: The GLI gene is a member of the Kruppel family of zinc finger proteins. Nature 332: 371-374, 1988.

26. Kasper M, Schnidar H, Neill GW, Hanneder M, Klingler S, Blaas L, Schmid C, Hauser-Kronberger C, Regl G, Philpott MP, et al: Selective modulation of Hedgehog/GLI target gene expression by epidermal growth factor signaling in human keratinocytes. Mol Cell Biol 26: 6283-6298, 2006.

27. Ruiz i Altaba A, Sánchez P and Dahmane N: Gli and hedgehog in cancer: Tumours, embryos and stem cells. Nat Rev Cancer 2: 361-372, 2002.

28. Ramalho-Santos M, Melton DA and McMahon AP: Hedgehog signals regulate multiple aspects of gastrointestinal development. Development 127: 2763-2772, 2000.

29. Taylor MD, Liu L, Raffel C, Hui CC, Mainprize TG, Zhang X, Agatep R, Chiappa S, Gao L, Lowrance A, et al: Mutations in SUFU predispose to medulloblastoma. Nat Genet 31: 306-310, 2002.

30. Tostar U, Malm CJ, Meis-Kindblom JM, Kindblom LG Toftgård $\mathrm{R}$ and Undén $\mathrm{AB}$ : Deregulation of the hedgehog signalling pathway: A possible role for the PTCH and SUFU genes in human rhabdomyoma and rhabdomyosarcoma development. J Pathol 208: 17-25, 2006.

31. Watkins DN, Berman DM, Burkholder SG, Wang B, Beachy PA and Baylin SB: Hedgehog signalling within airway epithelial progenitors and in small-cell lung cancer. Nature 422: 313-317, 2003.

32. Berman DM, Karhadkar SS, Maitra A, Montes De Oca R, Gerstenblith MR, Briggs K, Parker AR, Shimada Y, Eshleman JR, Watkins DN, et al: Widespread requirement for Hedgehog ligand stimulation in growth of digestive tract tumours. Nature 425 : $846-851,2003$

33. Rodova M, Fu J, Watkins DN, Srivastava RK and Shankar S: Sonic hedgehog signaling inhibition provides opportunities for targeted therapy by sulforaphane in regulating pancreatic cancer stem cell self-renewal. PLoS One 7: e46083, 2012.

34. Singh BN, Fu J, Srivastava RK and Shankar S: Hedgehog signaling antagonist GDC-0449 (Vismodegib) inhibits pancreatic cancer stem cell characteristics: Molecular mechanisms. PLoS One 6: e27306, 2011.

35. Magistri P, Battistelli C, Strippoli R, Petrucciani N, Pellinen T, Rossi L, Mangogna L, Aurello P, D'Angelo F, Tripodi M, et al: SMO inhibition modulates cellular plasticity and invasiveness in colorectal cancer. Front Pharmacol 8: 956, 2018.

36. Li X, Wang X, Xie C, Zhu J, Meng Y, Chen Y, Li Y, Jiang Y, Yang X, Wang S, et al: Sonic hedgehog and Wnt $/ \beta$-catenin pathways mediate curcumin inhibition of breast cancer stem cells. Anticancer Drugs 29: 208-215, 2018.

37. Morgan H, Olivero C and Patel GK: Identification of human cutaneous basal cell carcinoma cancer stem cells. Methods MolBiol: Apr 20, 2018 (Epub ahead of print). doi: 10.1007/7651_2018_133.

38. Tong W, Qiu L, Qi M, Liu J, Hu K, Lin W, Huang $\bar{Y}$ and Fu J: GANT-61 and GDC-0449 induce apoptosis of prostate cancer stem cells through a GLI-dependent mechanism. J Cell Biochem 119: 3641-3652, 2018.

39. Wang K, Pan L, Che X, Cui D and Li C: Glil inhibition induces cell-cycle arrest and enhanced apoptosis in brain glioma cell lines. J Neurooncol 98: 319-327, 2010.

40. Tsuda N, Ishiyama S, Li Y, Ioannides CG, Abbruzzese JL and Chang DZ: Synthetic microRNA designed to target glioma-associated antigen 1 transcription factor inhibits division and induces late apoptosis in pancreatic tumor cells. Clin Cancer Res 12: 6557-6564, 2006.

41. Bartel DP: MicroRNAs: Target recognition and regulatory functions. Cell 136: 215-233, 2009.

42. Cho WC: MicroRNAs in cancer - from research to therapy. Biochim Biophys Acta 1805: 209-217, 2010.

43. Guo S, Fesler A, Wang $\mathrm{H}$ and Ju J: microRNA based prognostic biomarkers in pancreatic Cancer. Biomark Res 6: 18, 2018.
44. Ventura A and Jacks T: MicroRNAs and cancer: Short RNAs go a long way. Cell 136: 586-591, 2009.

45. Nicoloso MS, Spizzo R, Shimizu M, Rossi S and Calin GA: MicroRNAs - the micro steering wheel of tumour metastases. Nat Rev Cancer 9: 293-302, 2009.

46. Fu J, Rodova M, Roy SK, Sharma J, Singh KP, Srivastava RK and Shankar S: GANT-61 inhibits pancreatic cancer stem cell growth in vitro and in NOD/SCID/IL2R gamma null mice xenograft. Cancer Lett 330: 22-32, 2013

47. Livak KJ and Schmittgen TD: Analysis of relative gene expression data using real-time quantitative PCR and the 2(-Delta Delta C(T)) method. Methods 25: 402-408, 2001.

48. Thiery JP, Acloque H, Huang RY and Nieto MA: Epithelialmesenchymal transitions in development and disease. Cell 139: 871-890, 2009.

49. Iwatsuki M, Mimori K, Yokobori T, Ishi H, Beppu T, Nakamori S Baba $\mathrm{H}$ and Mori M: Epithelial-mesenchymal transition in cancer development and its clinical significance. Cancer Sci 101: 293-299, 2010.

50. Wellner U, Schubert J,Burk UC,Schmalhofer O,Zhu F, Sonntag A, Waldvogel B, Vannier C, Darling D, zur Hausen A, et al: The EMT-activator ZEB1 promotes tumorigenicity by repressing stemness-inhibiting microRNAs. Nat Cell Biol 11: 1487-1495, 2009.

51. Hsieh TC, Wong C, John Bennett D and Wu JM: Regulation of p53 and cell proliferation by resveratrol and its derivatives in breast cancer cells: An in silico and biochemical approach targeting integrin $\alpha v \beta 3$. Int J Cancer 129: 2732-2743, 2011.

52. Hsieh TC, Huang YC and Wu JM: Control of prostate cell growth, DNA damage and repair and gene expression by resveratrol analogues, in vitro. Carcinogenesis 32: 93-101, 2011.

53. Fritz S, Fernández-del Castillo C, Iafrate AJ, Mino-Kenudson M, Neyhard N, LaFemina J, Stirman A, Warshaw AL and Thayer SP: Novel xenograft and cell line derived from an invasive intraductal papillary mucinous neoplasm of the pancreas give new insights into molecular mechanisms. Pancreas 39: 308-314, 2010.

54. Nissim S, Idos GE and Wu B: Genetic markers of malignant transformation in intraductal papillary mucinous neoplasm of the pancreas: A meta-analysis. Pancreas 41: 1195-1205, 2012.

55. Nolan-Stevaux O, Lau J, Truitt ML, Chu GC, Hebrok M, Fernández-Zapico ME and Hanahan D: GLI1 is regulated through Smoothened-independent mechanisms in neoplastic pancreatic ducts and mediates PDAC cell survival and transformation. Genes Dev 23: 24-36, 2009.

56. Lauth $\mathrm{M}$ and Toftgård R: Hedgehog signaling and pancreatic tumor development. Adv Cancer Res 110: 1-17, 2011

57. Thayer SP, di Magliano MP, Heiser PW, Nielsen CM, Roberts DJ, Lauwers GY, Qi YP, Gysin S, Fernández-del Castillo C, Yajnik V, et al: Hedgehog is an early and late mediator of pancreatic cancer tumorigenesis. Nature 425: 851-856, 2003.

58. Tang SN, Fu J, Nall D, Rodova M, Shankar S and Srivastava RK: Inhibition of sonic hedgehog pathway and pluripotency maintaining factors regulate human pancreatic cancer stem cell characteristics. Int J Cancer 131: 30-40, 2012.

59. Tang SN, Singh C, Nall D, Meeker D, Shankar S and Srivastava RK: The dietary bioflavonoid quercetin synergizes with epigallocathechin gallate (EGCG) to inhibit prostate cancer stem cell characteristics, invasion, migration and epithelial-mesenchymal transition. J Mol Signal 5: 14, 2010.

60. Kurahara H, Takao S, Maemura K, Mataki Y, Kuwahata T, Maeda K, Ding Q, Sakoda M, Iino S, Ishigami S, et al: Epithelial-mesenchymal transition and mesenchymal-epithelial transition via regulation of ZEB-1 and ZEB-2 expression in pancreatic cancer. J Surg Oncol 105: 655-661, 2012.

61. Pantel K, Alix-Panabières C and Riethdorf S: Cancer micrometastases. Nat Rev Clin Oncol 6: 339-351, 2009.

62. Baffa R, Fassan M, Volinia S, O'Hara B, Liu CG, Palazzo JP, Gardiman M, Rugge M, Gomella LG, Croce CM, et al: MicroRNA expression profiling of human metastatic cancers identifies cancer gene targets. J Pathol 219: 214-221, 2009.

63. Baranwal S and Alahari SK: miRNA control of tumor cell invasion and metastasis. Int J Cancer 126: 1283-1290, 2010.

64. Nalls D, Tang SN, Rodova M, Srivastava RK and Shankar S: Targeting epigenetic regulation of miR-34a for treatment of pancreatic cancer by inhibition of pancreatic cancer stem cells. PLoS One 6: e24099, 2011.

65. O'Brien SJ, Carter JV, Burton JF, Oxford BG, Schmidt MN, Hallion JC and Galandiuk S: The role of the miR-200 family in epithelial-mesenchymal transition in colorectal cancer: A systematic review. Int J Cancer 142: 2501-2511, 2018. 